\title{
Thyroid Hormone Action on Mitochondria
}

\author{
III. Resolution of lodine-Containing Mitochondria and Subfractions \\ by Zonal Centrifugation ${ }^{1}$
}

\author{
MICHAEL J. DIMINO, ROSEMARY A. KURAS, ALAN R. McClEARY, \\ AND FREDERIC L. HOCH
}

Departments of Biological Chemistry and Internal Medicine, The University of Michigan Medical School,
Ann Arbor, Michigan 48104

Received November 1, 1971; accepted March 28, 1972

\begin{abstract}
Mitochondria from the livers of normal rats and L-thyroxine $\left(\mathrm{LT}_{4}\right)$-injected rats $(5 \mu \mathrm{g} / \mathrm{g}, 2 \mathrm{hr}$ before killing) were studied by rate zonal centrifugation to detect early changes in physical properties and in composition. $\mathrm{LT}_{4}$ treatment causes the fractions containing intact liver mitochondria (as judged by succinoxidase activity) to significantly shift their distribution to the heavier end of a linear sucrose gradient, indicating an increase in sedimentation rate. Iodine distribution follows this shift in mitochondria. Iodine concentration increases 26 -fold in mitochondria from $\mathrm{LT}_{4}$-treated rats. In addition, iodine concentrates in the less dense part of the gradient in the $\mathbf{L T}_{4^{-}}$ treated group. Submitochondrial particles from the livers of injected rats were prepared by 15 min sonication and resolved by isopycnic zonal centrifugation. Distributions of iodine, cytochrome $a a_{3}$, RNA and monoamine oxidase activity indicate that $\mathrm{LT}_{4}$ is associated with the inner membrane of mitochondria.
\end{abstract}

Mitochondria from rat livers normally contain iodine $(1,2)$. Injecting rats with thyroxine $\left(\mathrm{LT}_{4}\right)^{2} 2$ min before killing increases the mitochondrial iodine content; about $75 \%$ of the new iodine is protein bound, of which $85 \%$ is extractable with butanol (3). Particles obtained after drastic sonication of mitochondria contain endogenous iodine and accumulate iodine after injection of $\mathrm{LT}_{4}(4)$. These findings, together with demonstrations of comparably early hormone-induced changes in mitochondrial oxidative phosphorylation $(5,6)$, suggest that a resolution of iodine-containing subfractions of mitochondria would be helpful in studying mechanisms of thyroid hormone action.

We have prepared liver mitochondria, ob-

1 This work was supported by grants from the NIH (AM13564) and from The John A. Hartford Foundation.

${ }^{2}$ Abbreviations used: $\mathrm{LT}_{4}$ : L-thyroxine; $\mathrm{MAO}$ : monoamine oxidase; $\mu \mathrm{g} \mathrm{AO}=\mu \mathrm{g}$ atoms of oxygen. tained from normal and $L^{\prime} T_{4}$-injected rats, by the usual differential centrifugation procedure. Further resolution of these mitochondria was achieved by rale zonal centrifugation in a shallow linear sucrose gradient. Mitochondrial subfractions were obtained by sonication and resolved by isopycnic zonal centrifugation. The iodine content of the fractions is here correlated with some measurements of composition and physical characteristics.

\section{MATERIALS AND METHODS}

Male rats weighing 150-200 g (Hormone Assay Company, Chicago, Ill) were kept on an ad lib. diet of Rockland Rat/Mouse Food. They were starved overnight before use in an experiment.

Livers were passed through a cold tissue press (Harvard Apparatus Company) and the pulp was homogenized in $0.25 \mathrm{~m}$ sucrose, $\mathrm{pH}$ 7.4. Heavy debris and cells were removed by spinning twice at $600 \mathrm{gav}_{\mathrm{av}}$ for $5 \mathrm{~min}$ in a refrigerated centrifuge. A mitochondrial fraction was sedimented at $13,500 g_{\mathrm{av}}$ for $20 \mathrm{~min}$ in a No. 30 rotor in a re- 
frigerated ultracentrituge (Spinco Division, Beckmian Instruments), and resuspended in $0.25 \mathrm{M}$ sucrose. The mitochondria were not washed, to minimize stress due to hydrostatic pressure and because it was expected that the subsequent zonal centrifugation would separate the microsomal contamination from the mitochondria.

Mitochondria from the livers of two rats were used for each rate zonal centrifugation study of intact mitochondria. In order, the following solutions were introduced into a zonal rotor ('I'i-14, Beckman) through the rim: (a) an initial discontinuous gradient, consisting of $50 \mathrm{ml}$ each of $12 \%$ (w/w) and $32 \%$ sucrose solutions; (b) a $400 \mathrm{ml}$ continuous shallow linear gradient ranging from $35 \%$ to $46.6 \%$; and (c) a $90 \mathrm{ml}$ cushion of $50 \%$ suerose. A $10 \mathrm{ml}$ mitochondrial sample and a $50 \mathrm{ml}$ overlay of $6.5 \%$ sucrose were then introduced through the core. The rotor was spun at $25,000 \mathrm{rpm}$ for $30 \mathrm{~min}$ to approximate an $\omega^{2} t$ value of $1.25 \times 10^{10}$, chosen because it gave excellent migration of the mitochondrial population from the sample zone but did not permit the isopycnic point to be reached by the majority of mitochondria. Twenty-four fractions of $25 \mathrm{ml}$ each were collected at the end of the run. To concentrate the mitochondrial fractions and to eliminate errors due to different sucrose concentrations, $2 \mathrm{ml}$ of water were added and the fractions were sedimented at $35,000 \mathrm{~g}_{\mathrm{av}}$ for $30 \mathrm{~min}$. The pellets then were resuspended in $0.25 \mathrm{~m}$ sucrose. To provide sufficient sample for the determination of cytochrome $a a_{3}$, monoamine oxidase (MAO) activity, and RNA, pellets from fractions 5 through 10 and from fractions 14 through 18 were combined. Four runs were made with mitochondria obtained from normal rats, and four with mitochondria obtained from rats killed $2 \mathrm{hr}$ after being injected with $5 \mu \mathrm{g}$ of $\mathrm{LT}_{4}$ per $\mathrm{g}$ body wt.

In studies on submitochondrial particles, mitochondria were prepared by differential centrifugation from the livers of $12 \mathrm{LT}_{4}$-injected rats, and were washed once. The mitochondria were sonicated (Sonifier Cell Disruptor, Heat Systems Company, Melville, NY) continuously for $15 \mathrm{~min}$ at $20 \mathrm{kc}$ and $90 \mathrm{w}$, in a chamber conoled with circulating alcohol from a dry ice bath at $-10^{\circ} \mathrm{C}$. Whole mitochondria and large mitochondrial fragments were removed by centrifuging at $24,000 \mathrm{~g}_{\mathrm{av}}$ for $20 \mathrm{~min}$. The supernatant, containing the submitochondrial particles and the mitochondrial matrix, was introduced into a zonal rotor containing a continuous sucrose gradient $(12-46.6 \%)$ and centrifuged at $45,000 \mathrm{rpm}$ for 20 hr to approximate an $\omega^{2} t$ value of $3.10 \times 10^{12}$. Thirty-three fractions of $20 \mathrm{ml}$ each were collected at the end of the run. The fractions were assayed directly for total iodine and protein, and protein values were corrected for interference due to sucrose concentrations (7). Sedimentable iodine, protein, cytochrome $a a_{3}$, MAO activity, and RNA in the fractions were measured after dilution with $30 \mathrm{ml}$ of water and centrifugation at $68,000 g_{\mathrm{av}}$ for $120 \mathrm{~min}$; the pellets were resuspended in $0.25 \mathrm{M}$ sucrose. Sucrose concentration in each fraction was determined with an Abbe refractometer. Results obtained by rate zonal centrifugation are presented as a percentage of the total recovered amount per fraction. In isopycnic zonal studies, fractions having the same average density are summed and the percentage of total recovered amount is plotted against density.

Succinoxidase activity was determined polarographically, measuring $\mathrm{O}_{2}$ consumption (Oxygraph, Gilson Medical Electronies). The reaction mixture, of $3 \mathrm{ml}$ volume, $\mathrm{pH} 7.4$, at $25^{\circ} \mathrm{C}$, contained $0.25 \mathrm{~m}$ sucrose, $7.4 \mathrm{~mm} \mathrm{KCl,} 7.4 \mathrm{~mm}$ Tris, $3.0 \mathrm{~mm}$ potassium mono- and dihydrogen phosphates, $0.16 \mathrm{~mm}$ EDTA, and $2.7 \mathrm{~mm}$ succinate.

MAO activity was determined by measuring the rate of formation of benzaldehyde from benzylamine (8). Protein was measured by the Lowry et al. method (9) using bovine serum albumin as a standard. RNA values were obtained by the method of Cooper et al. (10). Cytochrome $a a_{3}$ determination was based on difference spectra comparing the oxidized and reduced states (Amino-Chance dual-wavelength/split-beam recording spectrophotometer) (11). Iodine content was determined by a neutron activation method (12) that gives either 370 or $2400 \mathrm{cpm}$ per $\mathrm{ng}$ of iodine depending on the neutron flux used.

\section{RESULTS}

Mitochondria prepared from the livers of normal and $\mathrm{LT}_{4}$-injected $(5 \mu \mathrm{g} / \mathrm{g}, 2 \mathrm{hr}$ before killing) rats were subjected to rate zonal centrifugation, and each fraction was spun down and resuspended in $0.25 \mathrm{~m}$ sucrose. In Fig. 1, the mean total respiratory activity, and iodine and protein contents of each fraction are plotited as a percentage of the total amount of each recovered. About $50 \%$ of the succinoxidase activity of the initial mitochondrial preparation is recovered. Similar total succinoxidase activities are recovered in the fraction pellets for the normal and thyroxine-treated groups, 114 and $131 \mu \mathrm{g}$ A $0 / \mathrm{hr}$, respectively. The percentages of total respiratory activities in fractions 16 , 17 and 18 are significantly greater $(P<.01)$, and the percentages of total activities in fractions 14 and 15 are significantly lower $(P<.05)$, for thyroxine-treated than for 


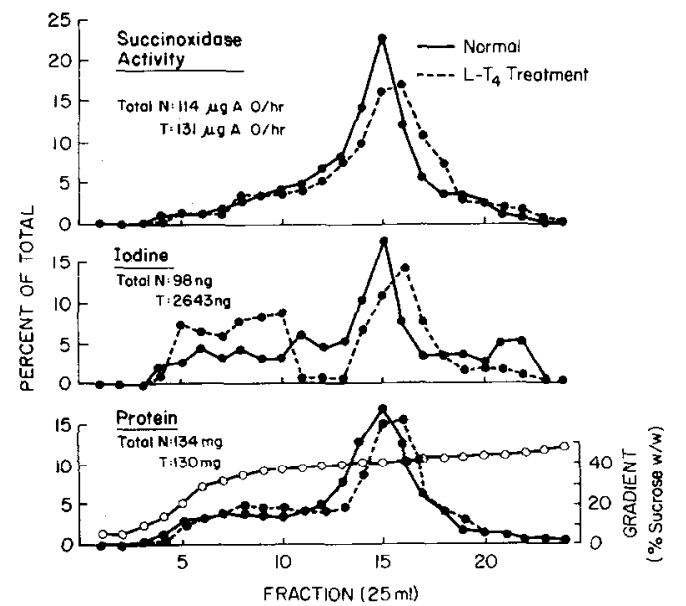

FIg. 1. Distributions of mitochondrial fractiuns prepared from normal and $\mathrm{LT}_{4}$-treated rats, after rate zonal centrifugation ran for 30 $\min$ at $25,000 \mathrm{rpm}\left(\omega^{2} t=1.25 \times 10^{10} ; \mathrm{Ti}-14\right.$ rotor, Beckman). Twenty-four fractions (25 ml each) were collected, and diluted with $2 \mathrm{ml}$ of water and sedimented at $35,000 \mathrm{~g}_{\mathrm{av}}$ for $30 \mathrm{~min}$. The pellets were resuspended in $0.25 \mathrm{~m}$ sucrose, and their succinoxidase activities, and iodine and protein contents were measured as described under Methods. The mean distributions of four zonal runs are expressed as percentages of total recovery per fraction. $N=$ normal, untreated $\operatorname{rats} ; T=$ rats injected with $\mathrm{LT}_{4}(5 \mu \mathrm{g} / \mathrm{g}) 2 \mathrm{hr}$ before sacrifice.

normal rats. Since mitochondria from both normal and treated rats reach their isopycnic point in fractions 17 and 18 , the shift toward the heavier end of the gradient indicates that the injection of the hormone increases the sedimentation rate of the mitochondria.

About $52 \%$ of the initial sample protein is in the fraction pellets (134 and $130 \mathrm{mg}$ for the normal and thyroxine-treated groups, respectively), and an additional $22 \%$ is found in soluble form in the first 7 fractions collected. No soluble protein is detected in fractions 8 through 24 , partly because high sucrose concentrations interfere with the assay of the low protein levels (7). Protein is distributed among the fractions much like the respiratory activity, although the protein peaks are somewhat broader. Pretreatment with $\mathrm{LT}_{4}$ also shifts the protein towards the heavier part of the sucrose gradient.

About $75 \%$ of the total iodine content of the original mitochondrial suspensions is recovered in the pellets of the fractions in both the normal and the $\mathrm{LT}_{4}$-treated groups. However, the total amount of iodine recovered in the fractions from treated rats is greater than in normals ( $2643 \mathrm{vs} .98 \mathrm{ng}$ ). The iodine in the mitochondria from either normal or hormone-treated rats is concentrated in fractions 14 through 18; hormone treatment shifts the iodine peak toward greater density as it does the protein and the succinoxidase activity. In addition, between fractions 5 and 10 there are minor peaks of iodine content in the normal, and a large broad peak in the $\mathrm{LT}_{4}$-treated group.

The light fractions (5-10) and the heavy fractions (14-18) have a higher specific iodine content (ng per mg protein) than the original mitochondrial suspensions, in mitochondria prepared from either normal or $\mathrm{LT}_{4}$-treated rats (Table I). In both cases, concentration of the iodine is $3-4$ times greater in the light fractions than in the dense fractions. However, $\mathrm{LT}_{4}$-treatment

\section{TABLE I}

Composition of Combined Mitochondrial Subfractions Obtained by Rate Zonal Centrifugation, Compared with Original Mitochondrial Sample ${ }^{a}$

\begin{tabular}{|c|c|c|c|c|}
\hline & Sample & $\begin{array}{l}\text { Orig- } \\
\text { inal } \\
\text { mito- } \\
\text { chon- } \\
\text { dria }\end{array}$ & $\begin{array}{l}\text { Com- } \\
\text { bined } \\
\text { frac- } \\
\text { tions } \\
5-10\end{array}$ & $\begin{array}{c}\text { Com- } \\
\text { bined } \\
\text { frac- } \\
\text { tions } \\
14-18\end{array}$ \\
\hline Iodine & $\mathrm{N}$ & 0.28 & 1.30 & 0.57 \\
\hline $\begin{array}{l}\text { (ng } \mathrm{mg}^{-1} \text { pro- } \\
\text { tein) }\end{array}$ & $\mathrm{LTT}_{4}$ & 9.24 & 57.00 & 13.90 \\
\hline Cytochrome $\mathrm{aa}_{3}$ & $\mathrm{~N}$ & 0.18 & 0.07 & 0.23 \\
\hline $\begin{array}{l}\text { (nmoles } \mathbf{m g}^{-1} \\
\text { protein) }\end{array}$ & $\mathbf{I}_{1} \mathbf{T}_{4}$ & 0.18 & 0.07 & 0.19 \\
\hline RNA & $\mathbf{N}$ & 59 & 162 & 12 \\
\hline ( $\mu \mathrm{g} \mathrm{mg}^{-1}$ protein) & $\mathrm{LT}_{4}$ & 68 & 171 & 14 \\
\hline $\begin{array}{c}\text { Monoamine oxidase } \\
\text { activity }\end{array}$ & & 5.5 & 4.5 & 7.8 \\
\hline $\begin{array}{l}\text { (nmoles benzal- } \\
\text { dehyde min }{ }^{-1} \\
\text { mg-1 protein) }^{-1}\end{array}$ & $\mathrm{LT}_{4}$ & 5.8 & 3.5 & 8.3 \\
\hline
\end{tabular}

a The treatment of the animals and the resolution of subfractions through zonal centrifugation are all as described in Fig. 1. Fractions 5-10 and 14-18 are combined to permit measurements of iodine, cytochrome $a a_{3}$, MAO activity, and RNA on the same samples. 


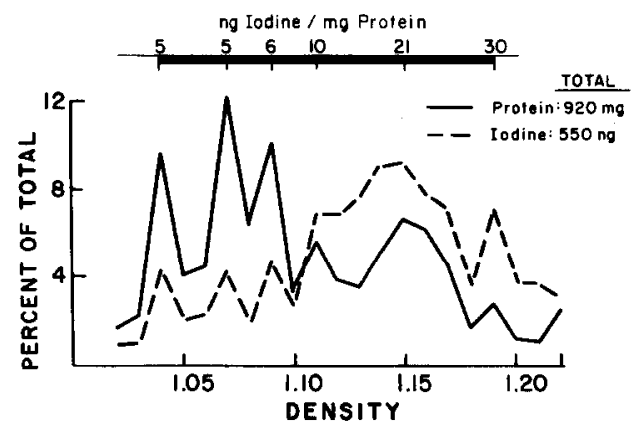

FIa. 2. Distributions of submitochondrial particles and soluble materials, prepared by $15 \mathrm{~min}$ sonication of mitochondria from $\mathrm{LT}_{4}$-treated rats, after isopyenic zonal centrifugation. Centrifugation was for $20 \mathrm{hr}$ at $45,000 \mathrm{rpm}\left(\omega^{2} t=3.10\right.$ $\times 10^{12}$; Ti-14 rotor, Beckman), in a linear sucrose gradient $(12-46.6 \%)$. Thirty-three fractions $(20$ ml each) were collected and their density, and protein and iodine contents were measured. Specific iodine contents for selected fractions are indicated.

increases the iodine content of the original mitochondrial suspension, the combined fractions $5-10$, and the combined fractions 14-18 to much higher levels than those of similar fractions from normal animals.

Pretreatment of rats with $\mathrm{LT}_{4}$ does not alter the MAO specific activity or the cytochrome $a a_{3}$ content in the original mitochondrial suspension or in the subfractions (Table I). In both the treated and the control groups, the light fractions contain less cytochrome $a a_{3}$ and MAO activity than the original suspensions and the heavy fractions. RNA concentration for both treated and control groups is 2-3 times higher in the light fractions, but 5 times lower in the heavy fractions, than in the original mitochondria. The intact mitochondria (heavy fractions) therefore contain virtually no microsomes.

Liver mitochondria were obtained from $\mathrm{LT}_{4}$-injected rats by differential centrifugation, washed once, and sonicated (see Methods). After removal of the intact mitochondria and heavy membrane fragments, the submitochondrial particles and soluble materials in the supernatant were resolved by isopyenic zonal centrifugation. Figure 2 shows the distributions of total protein and iodine. Most of the protein is in the lighter end of the gradient and most of the iodine is in the heavier end; within this general distribution there are minor peaks of iodine and protein which coincide. The highest protein peak is at a density of 1.07 and the highest iodine peak is at a density of 1.15 . Specific iodine content increases with the density, from $5 \mathrm{ng}$ iodine $/ \mathrm{mg}$ protein at a density of 1.04 to $30 \mathrm{ng}$ iodine/ $\mathrm{mg}$ protein at a density of 1.19 .

Because of low concentrations and interference from sucrose, cytochrome $a a_{3}, \mathrm{MAO}$ activity, and RNA content could not be measured accurately in each fraction. The separate fractions were therefore concentrated by sedimentation at $68,000 \quad g_{\mathrm{av}} \times$ $120 \mathrm{~min}$, and the pellets were suspended in 0.25 y sucrose. Recoveries after the zonal run and the subsequent centrifugation of the collected fractions are: iodine, $49 \%$; cytochrome $a a_{3}, 61 \%$; MAO activity, $37 \%$ and RNA, 36\%; and the distributions are shown in Fig. 3. Protein recovery (not shown) is $28 \%$ and the distribution resembles that of cytochrome $a a_{3}$. Iodine and cytochrome $a a_{3}$ have almost identical distributions, both peaking sharply at a density of 1.15. MAO activity has maxima at densities of 1.14 , 1.16 , and 1.19. RNA is distributed broadly around the densities of 1.16 and 1.17.

Incubating sonicated particles, obtained

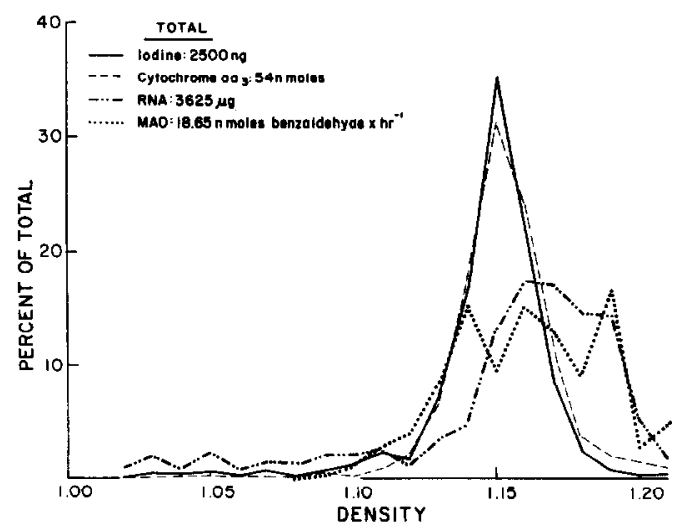

FIG. 3. Distributions of submitochondrial particles prepared and resolved as in Fig. 2. Each of the thirty-three fractions was diluted with 30 $\mathrm{ml}$ of water, sedimented at $68,000 \mathrm{gar}_{\mathrm{ar}}$ for 120 min, and resuspended in $0.25 \mathrm{~m}$ sucrose. MAO activity, iodine, cytochrome $a a_{3}$, and RNA contents were determined. 
the same way as in Fig. 3 , in $0.2 \%$ Triton $\mathrm{X}-100$ at $40^{\circ} \mathrm{C}$ for $30 \mathrm{~min}$ and resolving them isopycnically by zonal centrifugation does not significantly change the percentage recovered or the distributions of sedimentable iodine or cytochrome $a a_{3}$.

\section{DISCUSSION}

Taking succinoxidase activity as a marker for intact mitochondria, $\mathrm{LT}_{4}$-treatment increases the sedimentation rate of liver mitochondria within $2 \mathrm{hr}$. Because the isopyenic points of mitochondria from control and $\mathrm{LT}_{4}$ treated rats are similar, the increase in the sedimentation rate can be attributed to altered size and/or shape, but not to increased density. In euthyroid rats injected with $\mathrm{LT}_{4}$, the earliest changes in mitochondrial oxidative phosphorylation are found in 6-12 $\mathrm{hr}$ (5). The present studies demonstrate that physical alterations are detectable even earlier. The synthesis of a new population of liver mitochondria takes more than 4 days in such hormone-injected rats (13), so thyroxine here probably changes the properties of existing mitochondria. The size and shape of mitochondria respond to the energy state (14); there is evidence that $\mathrm{LT}_{4}$ controls the availability of high-energy intermediates (15).

When mitochondria are resolved by rate zonal centrifugation, the intact mitochondrial fractions (those with high succinoxidase activity) contain the preponderance of the total iodine; after hormone injection, most of the iodine accumulates in the intact mitochondria. The endogenous iodine and the iodine that appears after injection of $\mathrm{LT}_{4}$ secm to be handled similarly by rat liver mitochondria. In both cases the iodine is bound firmly enough to mitochondria to resist being removed in concentrated sucrose. This iodine binding persists after prolonged sonication of mitochondria from $L_{4}$-injected rats, after treatment of the sonicated mitochondrial subparticles with Triton X-100, and after further resolution by isopycnic zonal centrifugation. The sedimentable iodine appears to be bound to fragments of the inner membrane, as judged from its continued close correlation with cytochrome $a a_{3}$ content. ${ }^{3}$

Rate centrifugation also resolves iodine that is associated with particles that sediment slower than intact mitochondria, especially when the mitochondria are obtained from $\mathrm{LT}_{4}$-injected rats. The density of the sucrose solution makes it likely that these lighter fractions contain particles of the size of submitochondrial fragments or microsomes. The low cytochrome $a a_{3}$ content and MAO activity, and the high RNA content, suggest that an association between iodine and microsomes accounts for the high iodine:protein ratio in the light fractions. Hepatic microsomes contain a membrane-bound iodoprotein 40 $\mathrm{hr}$ after injection of thyroxine (16), and iodine does accumulate in microsomal fractions 5 min after injection of labeled $\mathrm{LT}_{4}$ (17). However, no hormone-induced changes in the function of ribosomes have been demonstrated at $2 \mathrm{hr}$ after injection (18).

The correlation between the localization of iodine and the functional capacities of the inner membrane fragments of rat liver mitochondria is under study.

\section{ACKNOWLEDGMENT}

The expert technical assistance of Mrs. M. R. Dockrill is acknowledged.

\section{REFERENCES}

1. Cakk, E. A., and Riggs, D. S. (1952) Biochem. J. $54,217$.

2. Dillon, R. S., AND Hoch, F. L. (1967) Biochem. Med. 1, 219.

3. Hoch, F. L., (1967) Proc. Nat. Acad. Sci. U.S.A. 58, 506.

4. Arbogast, B., ANd Hoch, F, L. (1968) Fed. Eur. Biol. Soc. Lett. 1, 315.

5. Hосн, F. L. (1968) Arch. Biochem. Biophys. $124,238$.

6. Носн, F. L. (1968) Arch. Biochem. Biophys. $124,248$.

7. Hinton, R. H., Burge, M. L. E., and HartMaN, G. C. (1969) Anal. Biochem. 29, 248.

8. Schnartman, C. A., Erwin, V. G., and GreenWALT, J. W. (1967) J. Cell Biol. 32, 719.

${ }^{3}$ Similar conclusions were reached by Tata et al. (Tata, J. R., Ernster, E., and Suranyi, E. M. (1962) Biochim. Biophys. Acta 60, 461). 
9. Lowry, O. H., Rosebrough, N. J., Farf A. L., AND RANDALL, R. J. (1951) J. Biol. Chem. 193, 265.

10. Cooper, W. K., Muramatsu, K., and WanneMaCHER, R. W. (1968) Biochim. Biophys. Acta 169, 269.

11. Williams, J. N. (1964) Arch. Biochem. Biophys. 107, 537.

12. Hoch, F. L., Kuras, R. A., and Jones, J. D (1971) Anal. Biochem. 40, 86.

13. Gross, N. J. (1971) J. Cell Biol. 48, 29.
14. Hackenbrock, C. R. (1968) J. Cell Biol. 37, 345.

15. НосH, F. L., (1972) Arch. Biochem. Biophys. 150,807

16. Kozyrefe, V., Surks, M. I., and OppenHEIMER, J. H. (1970) Endocrinology 86, 781.

17. Lee, M., and Williams, R. H. (1954) Endocrinology 54, 5 .

18. Sokoloff, L., Roberts, P. A., Januska, M. M., ANd Kline, J. E. (1968) Proc. Nat. Acad. Sci. U.S.A. 60, 652. 